\title{
THE 1971 SAN FERNANDO EARTHQUAKE: A DOUBLE EVENT?
}

\author{
By Thomas H. Heaton
}

\begin{abstract}
Evidence is presented which suggests that the 1971 San Fernando earthquake may have been a double event that occurred on two separate, subparallel thrust faults. It is postulated that the initial event took place at depth on the Sierra Madre fault zone which runs along the base of the San Gabriel Mountains. Rupture is postulated to have occurred from a depth of about $15 \mathrm{~km}$ to a depth of about $3 \mathrm{~km}$. A second event is thought to have initiated about $4 \mathrm{sec}$ later on another steeply dipping thrust fault which is located about $4 \mathbf{~ k m}$ south of the Sierra Madre fault zone. The surface trace of this fault coincides with the San Fernando fault zone which was the principal fault associated with surface rupture. It is postulated that rupture propagated from a depth of $8 \mathrm{~km}$ to the free surface. The moments of the first and second events are approximately $0.7 \times$ $10^{26}$ dyne-cm and $1.0 \times 10^{26}$ dyne-cm, respectively. This model is found to explain the combined data sets of strong ground motions, teleseismic $P$ and $S$ waveforms, and static offsets better than previous models, which consist of either a single fault plane or a plane having a dip angle which shallows with decreasing depth. Nevertheless, many features of the observed motions remain unexplained, and considerable uncertainty still exists regarding the faulting history of the San Fernando earthquake.
\end{abstract}

\section{INTRODUCTION}

The purpose of this study is to search for models of the 1971 San Fernando earthquake which are compatible with both local and teleseismic observations. This may seem at first glance to be an unexciting problem. After all, in the $10 \mathrm{yr}$ since the occurrence of this earthquake, there have been dozens of studies of the local and teleseismic records of the San Fernando earthquake. However, none of these studies has addressed one major problem: no single model proposed to date adequately explains both local and teleseismic observations of this earthquake. Furthermore, it is crucial to our understanding of seismic sources that such models be found. Unraveling the story contained within these records is our only hope for discovering the time history of the faulting which was responsible for this earthquake. Since the San Fernando earthquake has one of the most complete data sets to date, failure to obtain a consistent model from different types of data seriously undermines our ability to interpret earthquakes with less complete data sets.

I briefly review some significant findings of several previous studies which provide motivation for this work. From studies of the surface rupture (Bonilla et al., 1971; Kamb et al., 1971), focal mechanism (Whitcomb, 1971), and hypocentral location (Allen et al., 1973), it has long been recognized that a constantly dipping fault plane which is compatible with $P$-wave first-motion observations would not intersect both the hypocenter and the surface rupture (Allen et al., 1973). An obvious and simple solution to this problem is to assume that the fault changes dip angle somewhere between the hypocenter and the surface rupture. Many model studies have been based upon the premise that rupture proceeded unilaterally up-dip on a fault plane which decreases dip as the depth decreases. This assumption has been so often repeated that it has become somewhat dogmatic. Unfortunately, there is no direct evidence that the San Fernando earthquake occurred as a single rupture along a 
variably dipping fault plane. I later show that an alternative model of fault geometry is one which assumes that the earthquake was actually two events on two subparallel faults. I now trace the history of events which led to this alternate hypothesis.

Langston (1978) proposed a finite-fault model of the San Fernando earthquake which explained many of the features of both the long- and short-period teleseismic body waves recorded for this event. The model is relatively simple and consists of a uniform rupture which propagates up-dip at a rupture velocity of $1.8 \mathrm{~km} / \mathrm{sec}$. Langston tried several models which differed in the dip angle of the top part of the fault. He found that the teleseismic long periods fit best if the dip of the upper fault is $29^{\circ}$. A similar conclusion was reached by Bache and Barker (1978) from their study of teleseismic short-period $P$ waves. Studies of both strong ground motions (Boore and Zoback, 1974; Bache and Barker, 1978; Heaton and Helmberger, 1979) and static vertical offsets (Alewine, 1974) have also managed to explain features of this earthquake using a variably dipping fault assumption. However, none of these studies has demonstrated that a single model adequately explains both local and teleseismic data simultaneously.

In an earlier study of strong ground motion (Heaton and Helmberger, 1979), we produced synthetic strong ground motions for a model which was similar to the one Langston (1978) used to explain teleseismic body waves. We found that this model could not adequately explain the observed strong ground motions. However, by changing such parameters as rupture velocity and the distribution of faulting, we found a new model, Norma 163, which was much more compatible with observed strong ground motions. In this earlier study, we did not investigate the teleseismic body waves which would be produced from our local observation-based model, Norma 163. We reasoned that since Norma 163 was not greatly different from Langston's teleseismic model, we expected that our model would also explain the teleseismic records fairly well. Unfortunately, we have since discovered that Norma 163 does a poor job of explaining teleseismic long-period body waves. Upon further investigation, we discovered that it was extremely difficult to simultaneously explain both the teleseismic body-wave data and the strong-motion data with the type of model consisting of rupture along a single variably dipping fault plane. We further discovered that if we assume that the earthquake occurred on two subparallel steeply dipping faults, then it is possible to explain more adequately the combined teleseismic and local observations of the San Fernando earthquake.

In this paper, I will show why I believe that a model with a variably dipping fault plane is inconsistent with the data. I will then present synthetic records for a model consisting of two steeply dipping faults. Although I believe that such a model offers an attractive interpretation of the data, it will be clear that there is still much to be learned about this earthquake.

\section{The Data}

I will employ three different data sets in this study: long-period teleseismic body waves, strong ground motions, and static vertical ground deformations. Long-period teleseismic body waveforms are copied directly from Langston's (1978) study. He reviewed WWSSN and Canadian network data and, using the criteria of good signalto-noise ratio and azimuthal coverage, he selected 17 long-period vertical $P$ waveforms, 6 long-period $S H$ waveforms, and 8 long-period radial $S V$ waveforms. A full description of this data set is given in Langston's paper.

The locations of most of the accelerometers which recorded the San Fernando earthquake are shown in Figure 1. From this large set of locations, I have chosen 
five stations on the basis of distance to the fault and azimuthal coverage. The five stations we have chosen are Pacoima Dam (PAC), Holiday Inn (HLI), Jet Propulsion Laboratory (JPL), Lake Hughes Array Station 4 (LKH), and Pear Blossom Pumping Plant (PRB). These stations are indicated in Figure 1 by the codes C041, C048, G110, J142, and F103, respectively. These codes refer to the cataloging system used

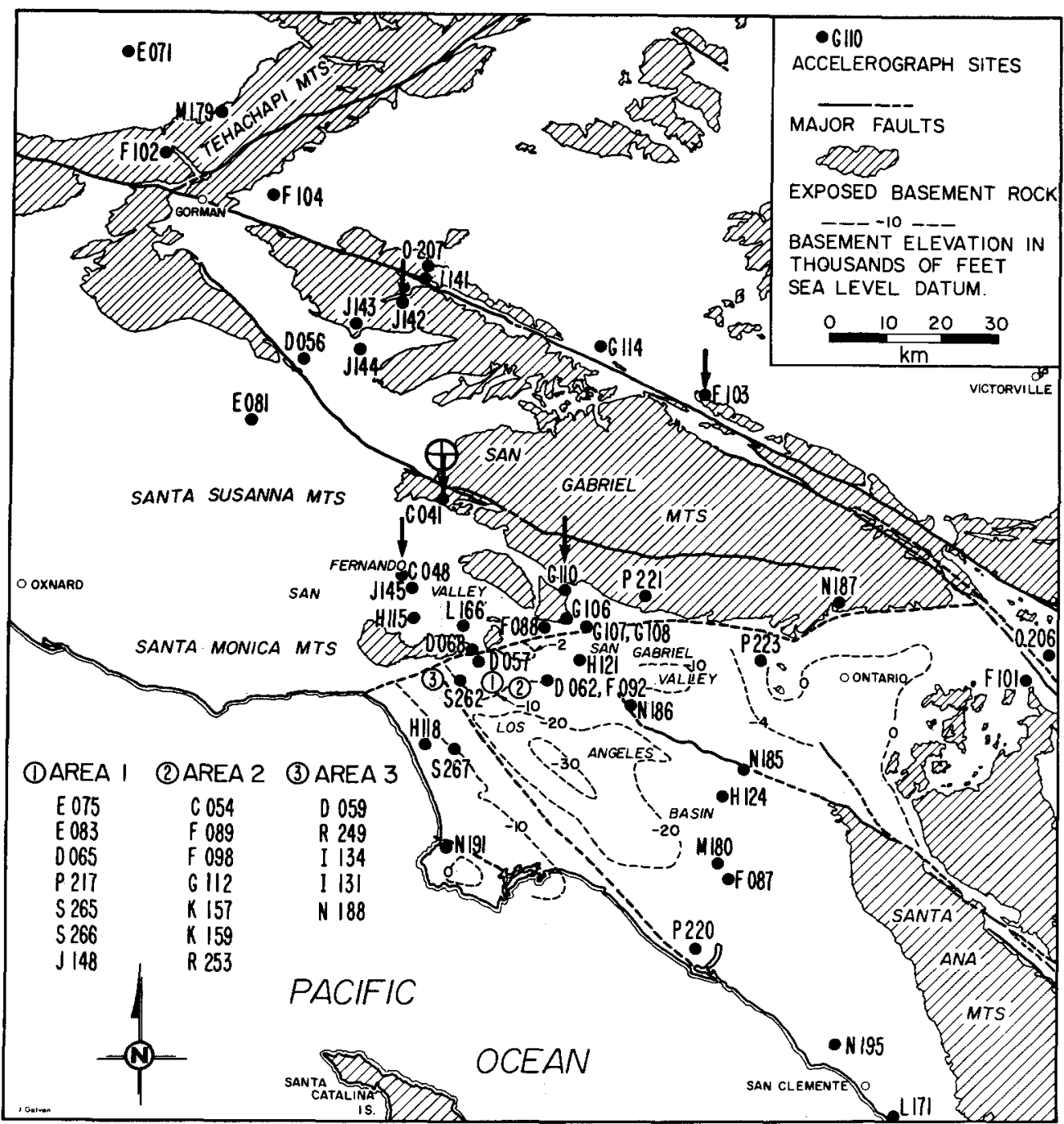

FIG. 1. The site locations of accelerometer recordings of the San Fernando earthquake are superimposed on the gross geological and structural features of the area. The encircled cross is the Allen et al. (1973) epicenter, and the arrows point to stations which are studied in this paper (modified from Hanks, 1975).

in the series of strong-motion data reports published by the Earthquake Engineering Research Laboratory of the California Institute of Technology. It is from these reports that I have taken observed ground motion. Because I am interested in explaining the overall faulting history, I have chosen to model the longer period parts of the strong ground motions. Thus for most stations, I have chosen to model the ground displacement history. Since very long-period ground motions generally 
cannot be recovered from accelerograms, the strong ground motions have been subjected to parabolic baseline correction and Ormsby filtering. Discussion of this processing can be found in Trifunac (1971), Trifunac et al. (1973a, b), and Hanks (1975).

Stations very close to faulting, such as Pacoima, may experience significant static offset during the course of strong shaking. Unfortunately, parabolic baseline corrections not only remove such static offset, but they can also introduce character which has little resemblance to actual ground motion. For this reason, I will also model observed ground velocity at Pacoima. These velocity records are obtained by direct integration of the digitized accelerograms and do not have parabolic baseline corrections.

The static vertical uplift data used in this study are taken directly from a compilation of such data assembled by Alewine (1974). He collected over 100 vertical displacement data points and constructed a contour map which summarizes these data. In this study, I assume that the vertical deformation is adequately represented by Alewine's contour map. Unfortunately, the horizontal deformation data seem less complete and reliable (Alewine, 1974) and will not be used in this study.

The model. The primary objective of this study is to produce synthetic displacements for both local and teleseismic observations using a consistent source model throughout the study. My model consists of a three-dimensional finite fault located within a half-space $(P$-wave velocity $=6.2 \mathrm{~km} / \mathrm{sec}, S$-wave velocity $=3.5 \mathrm{~km} / \mathrm{sec}$, density $=2.7 \mathrm{gm} / \mathrm{cm}^{3}$ ). I assume that a circular rupture front propagates at a given rupture velocity from the hypocenter. I also assume that the slip angle and dislocation time history are uniform everywhere on a fault plane. I further specify the absolute size of dislocation to be some arbitrary function of position on the fault.

I perform a summation of point source responses to compute synthetic ground motions. These point sources are located on a gridwork which covers the area of the fault. In the case of the strong-motion modeling, the Cagniard-de Hoop technique, together with a linear interpolation scheme, is used to compute responses to individual point sources. Exact Cagniard-de Hoop solutions are used to compute responses for our closest observation point, Pacoima. Fifth order asymptotic approximations of modified Bessel functions are used in the computations of responses at the other four strong-motion stations which are investigated. More complete descriptions of these techniques can be found in Heaton and Helmberger (1979) and particularly in Heaton (1978). Since 1400 point sources (130 of which are computed directly with Cagniard-de Hoop) are summed to construct synthetics for each station, computation of synthetic strong-motions is both time-consuming and expensive.

The computation of synthetic teleseismic body-wave motions for complex source models is surprisingly simple and inexpensive when compared to the strong-motion problem. Once again, a Green's function technique (point source summation) is employed. However, in this case, some very useful approximations can be made. These approximations and the nature of the resulting solutions are discussed in the Appendix.

Theoretical static offsets for an arbitrary three-dimensional finite fault located in a half-space are also computed by using a Green's function integration technique. Once again, the fault is subdivided into a gridwork (1- $\mathrm{km}$ squares) where the dislocation is homogeneous within each grid, but the dislocation varies from one grid to another. The analytic expressions of Mansinha and Smylie (1971) are used 
to calculate the surface offset due to each fault grid. A linear summation of all of the fault grids yields the final solution.

Variable-dip single-fault model. In this section, I will describe the problems I encountered when trying to explain both local and teleseismic data sets using models which consist of a single fault whose dip shallows as depth decreases. A crosssectional view of the fault geometry, which was proposed by Langston (1978) from teleseismic studies and which we later assumed in our strong-motion study (Heaton and Helmberger, 1979), is shown in Figure 2. Recall that Langston found that this type of model could explain the teleseismic body waves using the simple assumption that the size of dislocation does not vary with depth along the fault. $\mathrm{He}$ also demonstrated that a rupture velocity of $1.8 \mathrm{~km} / \mathrm{sec}$ would best fit teleseismic records if such a fault geometry was chosen. Our study of strong ground motions, however, indicated that this simple rupture model is not compatible with observed ground motions. In particular, we demonstrated that uniform shallow faulting beneath the strong-motion station, PAC, would produce large vertical displacements at PAC,

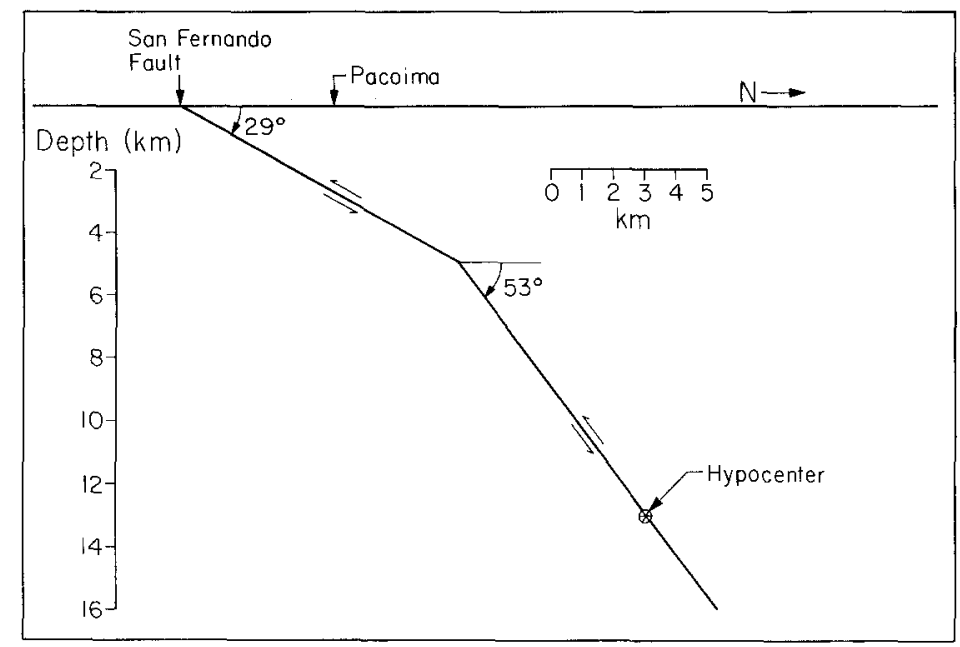

FIG. 2. Cross-sectional view of fault geometry which consists of a single fault whose dip shallows as depth decreases. The geometry was proposed by Langston (1978) and assumed in our earlier study of strong ground motions (Heaton and Helmberger, 1979).

but these cannot be seen in the data. In order to alleviate this problem, we proposed a model in which most of the dislocation on the shallow-dipping portion of the fault plane is concentrated near the free surface and to the south of PAC. This conclusion was in agreement with Alewine's (1974) modeling of the vertical static offsets produced by the San Fernando earthquake. In order to explain the timing of pulses at $\mathrm{PAC}$, we also proposed that the rupture velocity was $2.8 \mathrm{~km} / \mathrm{sec}$ on the steeply dipping portion of the fault and $1.8 \mathrm{~km} / \mathrm{sec}$ on the shallow-dipping portion. This is a significantly higher rupture velocity than that derived from the teleseismic records by Langston. Although at the time of our earlier study, we recognized that our model, Norma 163, might not explain the teleseismic records as well as Langston's model, we felt that Norma 163 would probably do an acceptable job, since the fault geometry and the relative moments of the steep and shallow-dipping parts of the fault were roughly the same as those used by Langston. We did not anticipate just how poorly Norma 163 would fit the teleseismic records.

Strong ground motions. In Figure 3, I show the model Norma 163 along with a 

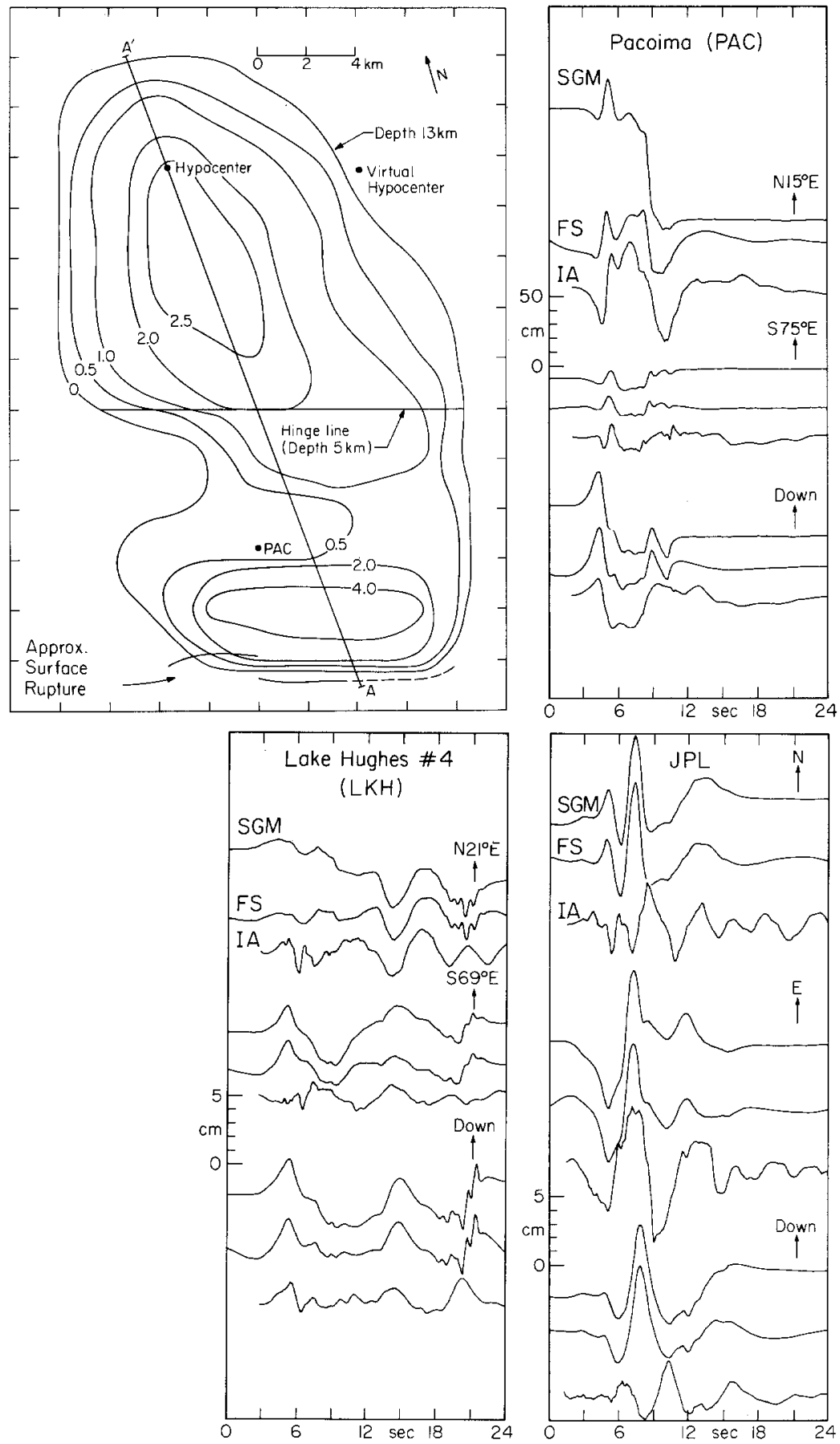

FrG. 3. Summary of the model Norma 163, proposed in our earlier study (Heaton and Helmberger, 1979). A contour map of the assumed dislocation (in meters) is shown in the upper left. The details of the rupture process are given in Table 1. Also shown are comparisons of observed and synthetic displacements for the stations PAC, JPL, and LKH. The top trace is the synthetic ground motion (SGM); the middle trace is this synthetic ground motion after baseline correction and Ormsby filtering (FS), and the bottom trace is the observed displacement which has also been filtered and baseline corrected (IA). 
comparison of synthetic and observed strong ground motions at the stations PAC, JPL, and LKH. The contours signify lines of equal dislocation in meters. The rupture front spreads radially from the hypocenter at a velocity of $2.8 \mathrm{~km} / \mathrm{sec}$ and then slows to $1.8 \mathrm{~km} / \mathrm{sec}$ as it ruptures the shallow-dipping part of the fault. The time derivative of the time history of slip for each point on the fault is an isosceles triangle with a duration of $0.8 \mathrm{sec}$. A full description of the parameters assumed for Norma 163 is given in Table 1.

Comparisons of synthetic and observed strong ground motions for Norma 163 are also shown in Figure 3. Two synthetic records are shown for each component of motion. The top trace is computed ground motion and the middle trace is this synthetic motion with a baseline correction and high-pass Ormsby filter applied. We used the baseline correction described by Nigam and Jennings (1968), and an 8-sec Ormsby filter. This filter is described by Hanks (1975). A detailed description of the seismic phases which comprise these synthetics can be found in our earlier paper (Heaton and Helmberger, 1979).

Although it is clear that the synthetics do not match all of the arrivals present in the data, it is also clear that this model explains many of the major features of these

TABLE 1

\begin{tabular}{lcc}
\multicolumn{3}{c}{ SourCe PARAMETER FOR NoRMA 163} \\
\hline & $\begin{array}{c}\text { Lower } \\
\text { Segment }\end{array}$ & $\begin{array}{c}\text { Upper } \\
\text { Segment }\end{array}$ \\
\hline Depth of hinge (km) & \multicolumn{2}{c}{5.0} \\
Strike & $-75^{\circ}$ & $-75^{\circ}$ \\
Dip & $53^{\circ}$ & $29^{\circ}$ \\
Rake & $76^{\circ}$ & $90^{\circ}$ \\
Rupture velocity (km/sec) & 2.8 & 1.8 \\
Rise time (sec) & 0.8 & 0.8 \\
Moment (X 10 ${ }^{26}$ dyne-cm) & 0.8 & 0.6 \\
Hypocentral longitude & $118.41^{\circ} \mathrm{E}$ & $118.33^{\circ} \mathrm{E}$ \\
Hypocentral latitude & $34.44^{\circ} \mathrm{N}$ & $34.42^{\circ} \mathrm{N}$ \\
Hypocentral depth $(\mathrm{km})$ & 13 & 13 \\
\hline
\end{tabular}

records much better than our starting model which had relatively uniform faulting throughout.

Teleseismic body waves. Comparisons of synthetic and observed teleseismic longperiod vertical $P$ waveforms for Norma 163 are shown in Figure 4. All amplitudes have been normalized such that the number listed beside each record is the moment ( $\times 10^{26}$ dyne-cm) which produces identical peak amplitudes for the observed and synthetic records. A lower hemispherical projection of the locations of stations, as well as the $P$-wave nodal planes for the two parts of the hinged fault, are shown. The most obvious feature of this figure is the fact that there is a poor match between the synthetics and the data. Furthermore, the matches attained by Langston (1978) are far superior. The major deficiency in the synthetics is the lack of a strong secondary peak which is universally present in the data. Further analysis of the synthetics produced by Langston's model reveals that this second peak is produced by the shallow-dipping portion of the fault. It can also be shown that most of the energy in this second arrival comes from the part of the fault which lies between depths of 5 and $3 \mathrm{~km}$. For a shallow dip-slip fault, there is a strong destructive interference between the direct $P$ phase and the combined $p P$ and $s P$ phases. When 
the source depth is very small, these phases all arrive very closely in time and almost total annihilation occurs. Thus, it is virtually impossible to synthetically produce a large second arrival with very shallow (less than $3 \mathrm{~km}$ ) thrust faulting.

I am faced with a dilemma. Modeling of strong ground motions indicates that only small dislocations are acceptable on that portion of the fault which lies beneath $\mathrm{PAC}$ at depths between 5 and $2.5 \mathrm{~km}$. Modeling of teleseismic long-period $P$ waves, however, indicates that significant faulting in just this depth range provides a reasonable interpretation of the data. It appears that it is very difficult to satisfy both the strong-motion and teleseismic data using the fault geometry chosen by Langston and also used in our earlier study. Despite this difficulty, the teleseismic

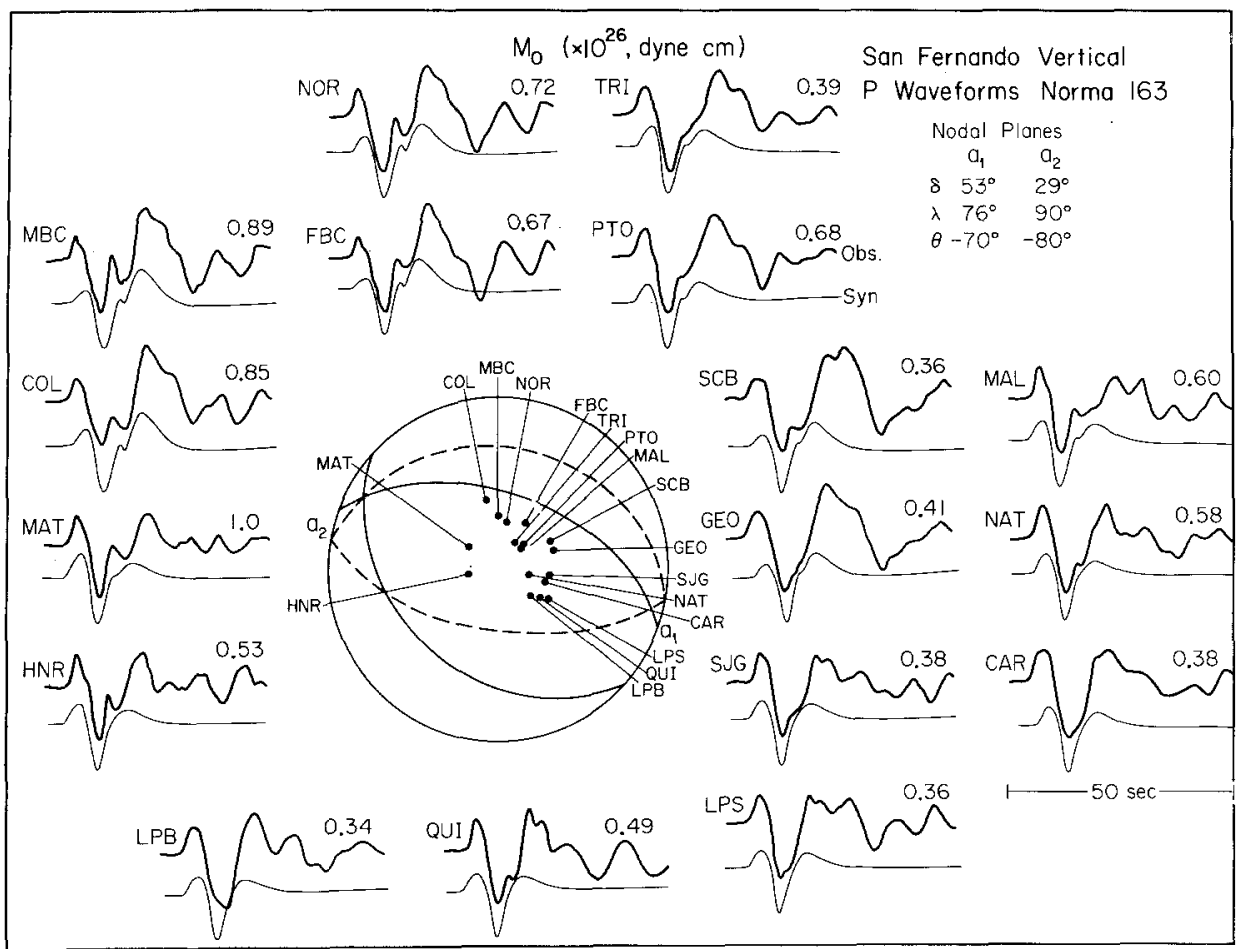

FIG. 4. Observed (top) and synthetic (bottom) long-period vertical $P$ waveforms at 17 WWSSN and Canadian network stations for the fault model Norma 163. Lower hemispherical projections of station locations are shown, as well as the nodal planes of both the bottom (solid lines) and top (dashed lines) sections of the fault model. The numbers above each record are the moments $\left(\times 10^{26}\right.$ dyne-cm) which produce equal peak amplitudes of synthetic and observed records. The observed records have been copied from Langston (1978).

and strong-motion data both indicate that some second source is important in this earthquake. The strong-motion data and the static offset data also indicate that there was significant shallow faulting, and this shallow faulting is the most likely candidate for the second source. How can we construct a model for which the second source produces the large shallow faulting and also extends to a great enough depth to be seen teleseismically, but does not involve significant faulting at very shallow depths beneath PAC? I believe that changing the fault geometry offers the simplest way out of this dilemma. If I assume that the dip of the shallow source is significantly steeper than $29^{\circ}$, then it is possible for the second source to extend to greater depths without passing beneath $\mathrm{PAC}$ at a shallow depth. 


\section{Constant Dip Two-Fault Model}

In this section, I describe a model having two distinct events which occur on offset subparallel thrust faults. A cross section of the assumed fault geometry is shown in Figure 5. I will assume that the two faults coincide with mapped geologically active faults, and the San Fernando and Sierra Madre fault zones. I will assume that the dip of the Sierra Madre fault zone is $54^{\circ}$. This dip is not only compatible with the $P$-wave focal mechanism, but the up-dip projection of this plane from the calculated hypocenter also conveniently intersects the surface near the mapped trace of the Sierra Madre fault zone. As has been the case from the beginning, there is little constraint on the dip of the San Fernando fault zone, and in this model I have assumed a value of $45^{\circ}$. The two faults differ in strike by $5^{\circ}$. The strike of the San Fernando fault zone is constrained by the average mapped surface rupture. The strike of the Sierra Madre fault zone is constrained by both the $P$-wave focal mechanism and the mapped surface trace, which agree almost exactly. I actually

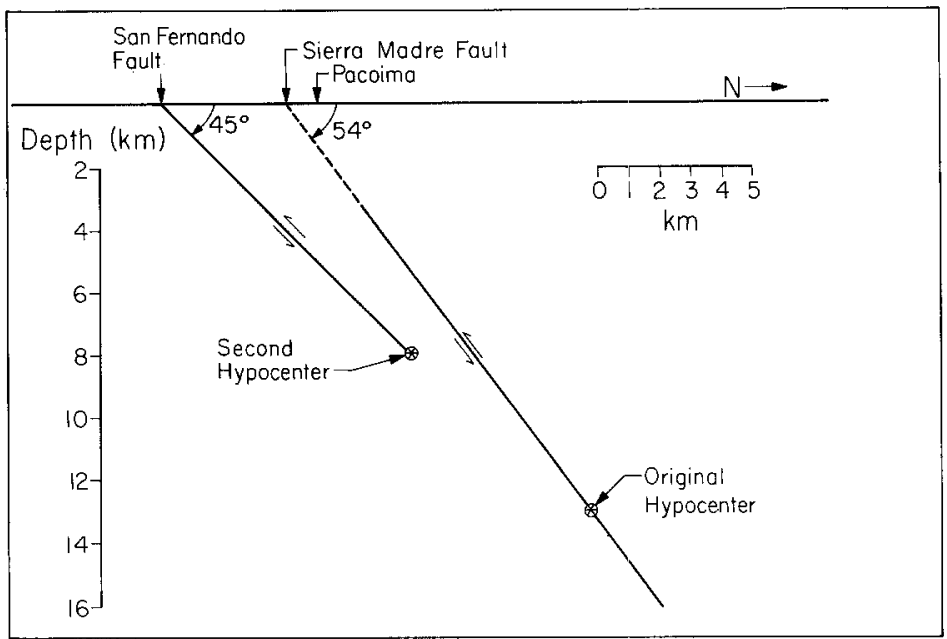

FIG. 5. Cross-sectional view of fault geometry which consists of two subparallel thrust faults. This is the fault geometry assumed for model 20L2-21U2 which is described in Table 2.

constructed several dozen models which incorporate the geometry described above. These models vary in the assumed timing and distribution of faulting. In this paper, I have chosen to present the model 20L2-21U2 whose faulting distribution is shown in Figure 6. Once again, the contours signify lines of equal dislocation. The hypocenters of both events are also shown, and they occur at depths of 13 and $8 \mathrm{~km}$. Rupture is assumed to spread radially at a velocity of $2.8 \mathrm{~km} / \mathrm{sec}$ in both events. Rupture on the San Fernando fault zone begins $4.0 \mathrm{sec}$ after the initiation of rupture on the Sierra Madre fault zone. The dislocation time history is uniform within each fault, but is significantly longer for the San Fernando fault zone. A complete description of the model parameters can be found in Table 2 . There are many details in 20L2-21U2 and many of these are rather arbitrarily chosen. I will, however, try to justify certain features of the model.

Teleseismic body waves. I show a comparison of synthetic and observed longperiod teleseismic $P$ waveforms in Figure 7 . As before, the amplitudes have been 

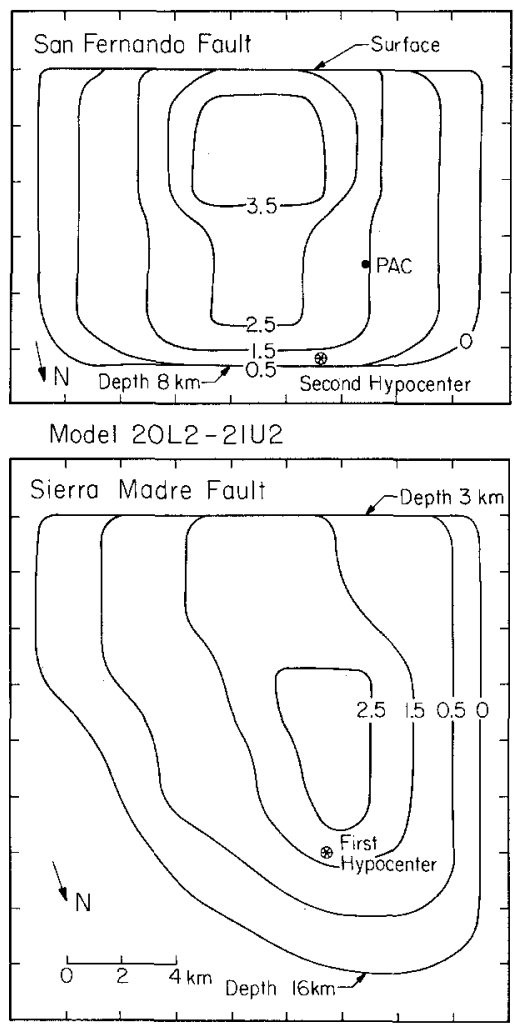

FIG. 6. Contour map of the dislocation distribution (in meters) assumed for the model 20L2-21U2 which is described in Table 2.

Table 2

Source parameters for model 2OL2-2IU2

$\begin{array}{lcc} & \text { Sierra Madre Fault } & \text { San Fernando Foult } \\ \text { Strike } & 290^{\circ} & 285^{\circ} \\ \text { Dip } & 54^{\circ} & 45^{\circ} \\ \text { Rake } & 76^{\circ} & 90^{\circ} \\ \text { Moment }\left(\times 10^{26} \text { dyne }-\mathrm{cm}\right) & 0.7 & 1.0 \\ \text { Rupture Velocity }(\mathrm{km} / \mathrm{sec}) & 2.8 & 2.8 \\ \text { Hypocentral Depth }(\mathrm{km}) & 13.0 & 8.0 \\ \text { Time Lag }(\mathrm{sec}) & - & 4.0 \\ \text { D }(1) & \end{array}$

normalized such that the number listed beside each record is the moment $\left(\times 10^{26}\right.$ dyne-cm) which produces identical peak amplitudes for the observed and synthetic records. A comparison of Figure 4 (Norma 163) and Figure 7 quickly reveals that the 20L2-21U2 does a much better job fitting the observed records than does Norma 
163. Although there are significant differences between 20L2-21U2 and Langston's (1978) model, the synthetics are roughly comparable. Perhaps the most striking difference between Langston's model and 20L2-21U2 is the rupture velocity. He used a rupture velocity of $1.8 \mathrm{~km} / \mathrm{sec}$ throughout, whereas I used a rupture velocity of $2.8 \mathrm{~km} / \mathrm{sec}$. My choice of a higher rupture velocity is controlled by my modeling of strong ground motions. In fact, it appears that the durations of my synthetic teleseismic records are shorter than the observed. A lower rupture velocity would help to alleviate this. Unfortunately, it is difficult to explain strong ground motions with a low rupture velocity. 20L2-21U2 contains several features which were specifically designed to lengthen the duration of the teleseismic signal. To begin with, there is significant overlap in depth of the ruptures on the San Fernando and Sierra Madre fault zones. This lengthens the teleseismic pulses since longer times are

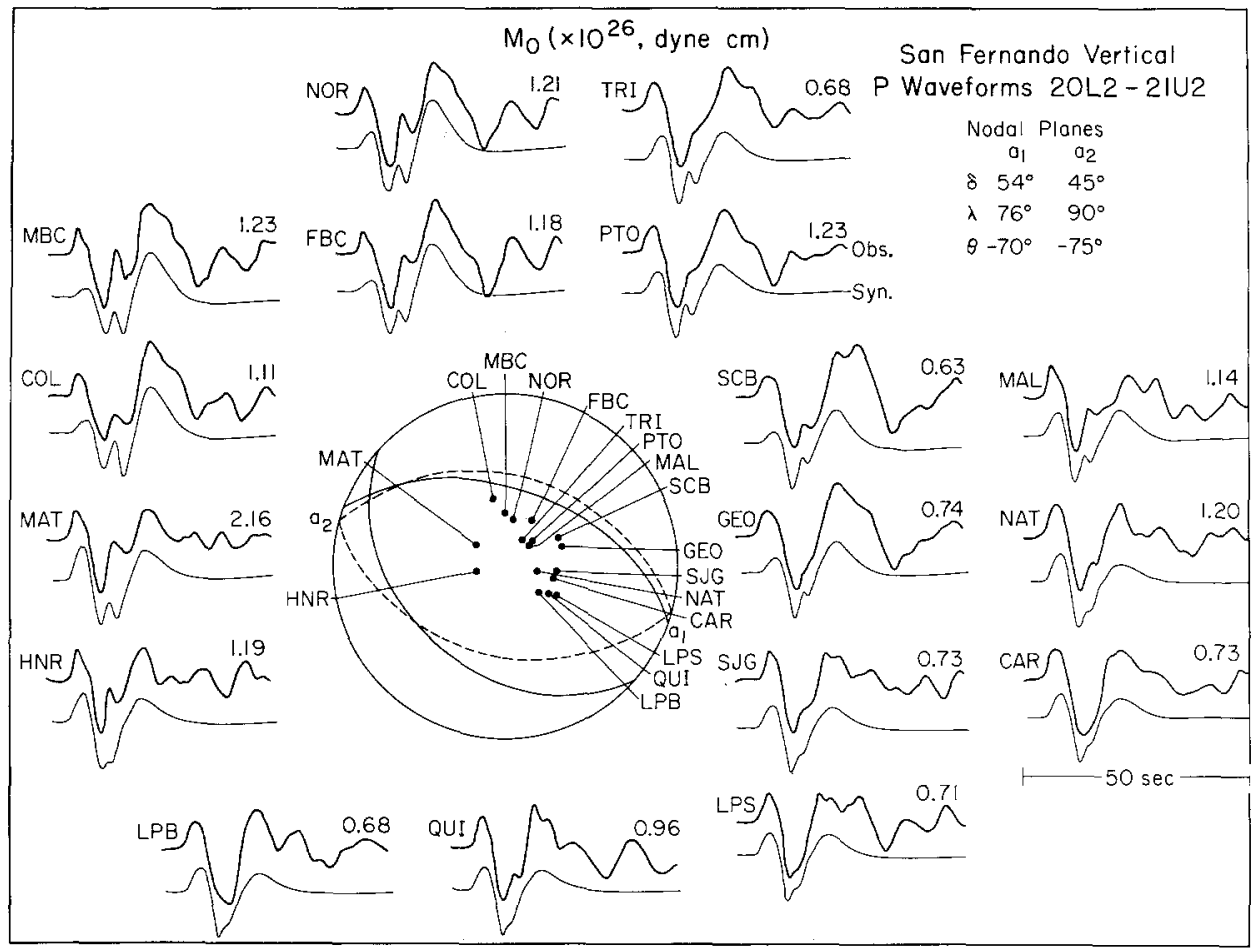

Fig. 7. Observed (top) and synthetic (bottom) $P$ waveforms for model 20L2-21U2. See Figure 4 for a more detailed figure explanation.

required to rupture these wider faults. I have also assumed a fairly complex time history for dislocations on the San Fernando fault zone. The first half of the dislocation occurs within the first $0.8 \mathrm{sec}$, whereas the second half of the dislocation occurs smoothly over the next $3.5 \mathrm{sec}$. The slow part of this dislocation helps to lengthen the long-period teleseismic arrivals.

The average total moment, which I obtained from fitting teleseismic $P$ waves, is $1.03 \times 10^{26}$ dyne-cm. Although this figure is somewhat higher than that derived by Langston $\left(0.86 \times 10^{26}\right.$ dyne-cm), this difference is not particularly noteworthy since $I$ assumed a $t^{*}$ of 1.2 whereas Langston assumed a $t^{*}$ of 1.0 for teleseismic $P$ waves. Of greater concern is the discrepancy between the moment obtained from fitting teleseismic $P$ waves and the moment obtained from fitting the strong-motion records. The moment given in Table 2 and reflected in the dislocation contours of 
Figure 6 is $1.7 \times 10^{26}$ dyne-cm and was deduced from the strong-motion modeling. Although I note this discrepancy, I will not explain it.

The azimuthal variation in amplitudes may also show some systematics. It appears that stations in northern azimuths yield higher moments than stations at other azimuths. Although the long-period $P$ waveforms appear to vary smoothly with azimuth, their absolute amplitudes do not. This feature seems characteristic of longperiod teleseismic $P$ waves and, to date, a complete explanation of this phenomenon is unavailable.

In Figure 8, I show a comparison of synthetic and observed long-period teleseismic $S H$ waveforms for 20L2-21U2. Although there are obvious deficiencies in the model, the match between data and synthetics is fairly good. In some respects, 20L2-21U2 explains these observations better than Langston's model. The average moment derived from the $S H$ waves is $1.5 \times 10^{26}$ dyne-cm which agrees favorably with the moment derived from strong-motion modeling. This is significantly higher than the

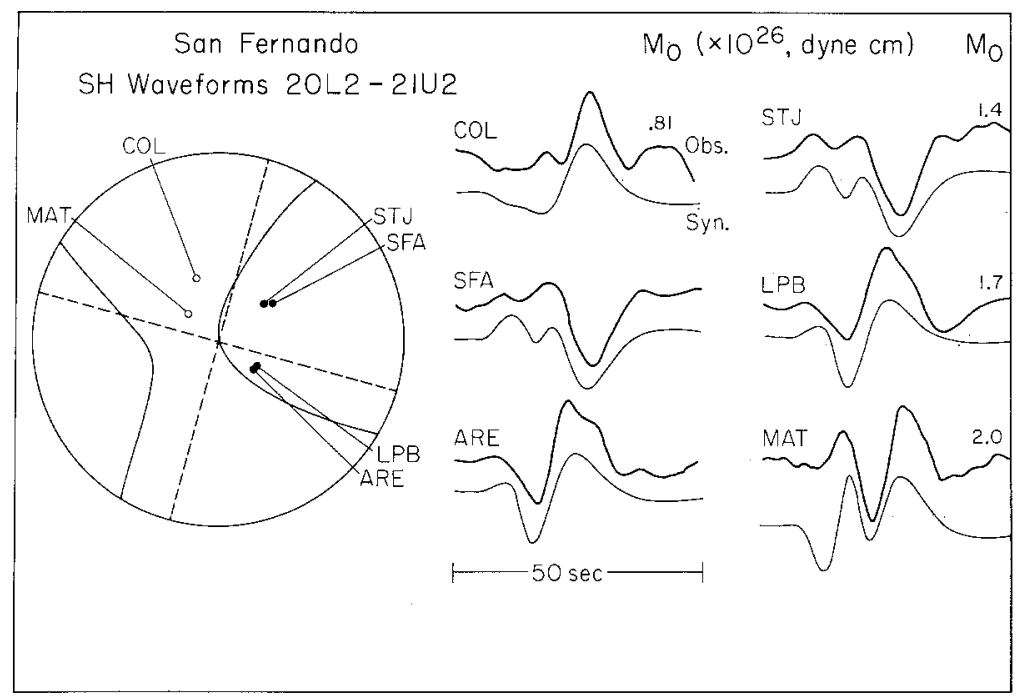

FIG. 8. Observed (top) and synthetic (bottom) long-period transverse $S H$ waveforms for model 20L221U2. The same scheme is used here as for Figure 4. The observed records have been copied from Langston (1978).

value of $0.6 \times 10^{26}$ dyne-cm that Langston obtained from modeling the same records. This difference cannot be explained by the high $t^{*}(4.8$ versus 4.0$)$ that I assumed in this study.

Comparisons of synthetic and observed long-period teleseismic radial $S V$ waveforms for 20L2-21U2 are shown in Figure 9. Teleseismic $S V$ waveforms are often affected by complex crustal effects (Burdick and Langston, 1977). S-coupled $P_{L}$ waves, which are characterized by long-period prograde-elliptical particle motions, often seriously contaminate $S V$ waveforms within a short time after the first arrival of the $S V$ wave. I have followed the suggestion of Langston (1978) that the first 20 sec of $S V$ wave shown in Figure 9 are probably a good representation of $S V$ radiation and interaction in the source area. A comparison of the data and synthetics shows that, although there are some fairly serious problems with the timing, there is also a reasonably good correspondence between the waveforms. It is clear, though, that 20L2-21U2 does not match the $S V$ waveforms as well as it matches either the long- 
period $P$ or $S H$ waves. At present, I can only speculate that including a more realistic earth transfer function for $S V$ waves may improve the synthetics.

Strong ground motions. In Figure 10, I show a comparison of synthetic and observed strong ground motion records for $20 \mathrm{~L} 2-21 \mathrm{U} 2$. Two synthetic records are shown for each component of motion. The top trace is computed ground motion, whereas the middle trace is the synthetic ground motion with a baseline correction and Ormsby filter applied. The middle trace is to be compared with the bottom trace, which is the observed displacement data and which has also been baseline corrected and Ormsby filtered. Because of the rather severe distortion of synthetic ground motions for PAC that are caused by the baseline correction, I have also found it useful to examine the ground velocity which is less affected by this correction. In this part of the figure, the top trace is the synthetic ground motion, the middle trace is the synthetic ground velocity, and the bottom trace is the observed ground velocity.

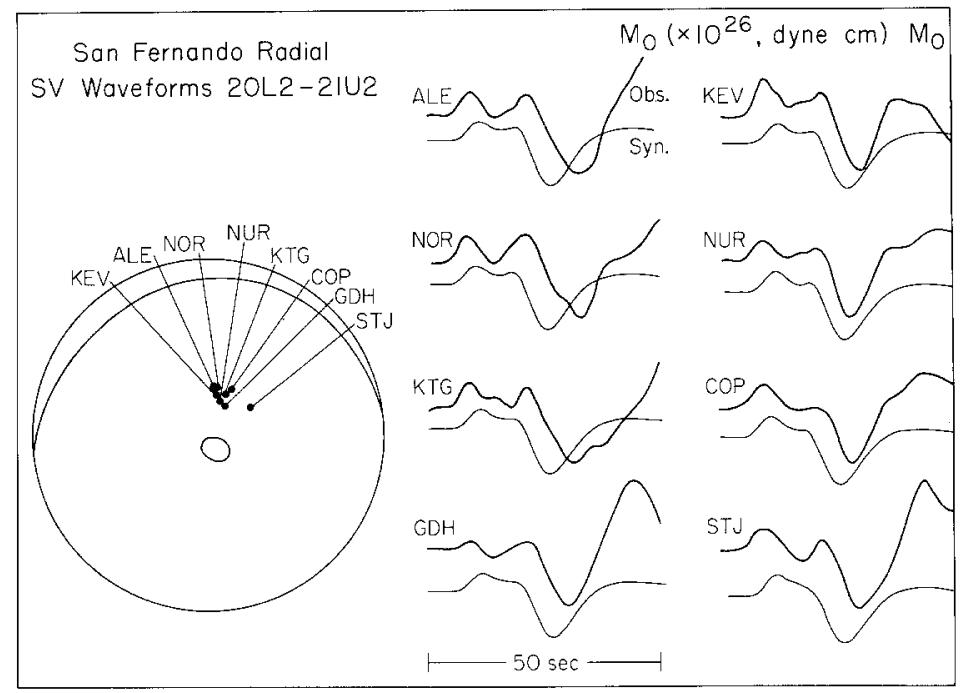

FIG. 9. Observed (top) and synthetic (bottom) long-period radial $S V$ waveforms for model 20L2-21U2. The same scheme is used here as for Figure 4. The observed records have been copied from Langston (1978).

Probably the first thing I notice when comparing the observed and synthetic records is that the model does not fit the strong ground motions nearly as well as it does the teleseismic body waves. Furthermore, it does not fit the strong motions quite as well as our previous model, Norma 163. This is regrettable and can be attributed to my strong desire to fit teleseismic body waves. That is, I am trying to fit many data with the same model and tradeoffs between goodness of fit and between the many observations inevitably occur.

Let me now begin by studying the comparison of observed and synthetic records for PAC. This station is located on crystalline basement in the immediate epicentral vicinity and, thus, it is probably the observation which is most likely to be modeled by my crude homogeneous half-space model. As can be seen in the velocity records, 20L2-21U2 explains the shape of the strong velocity pulse at the beginning of the record quite well. However, the vertical component of the synthetic record is too large, whereas the horizontal components are too small. In my model, this pulse is 

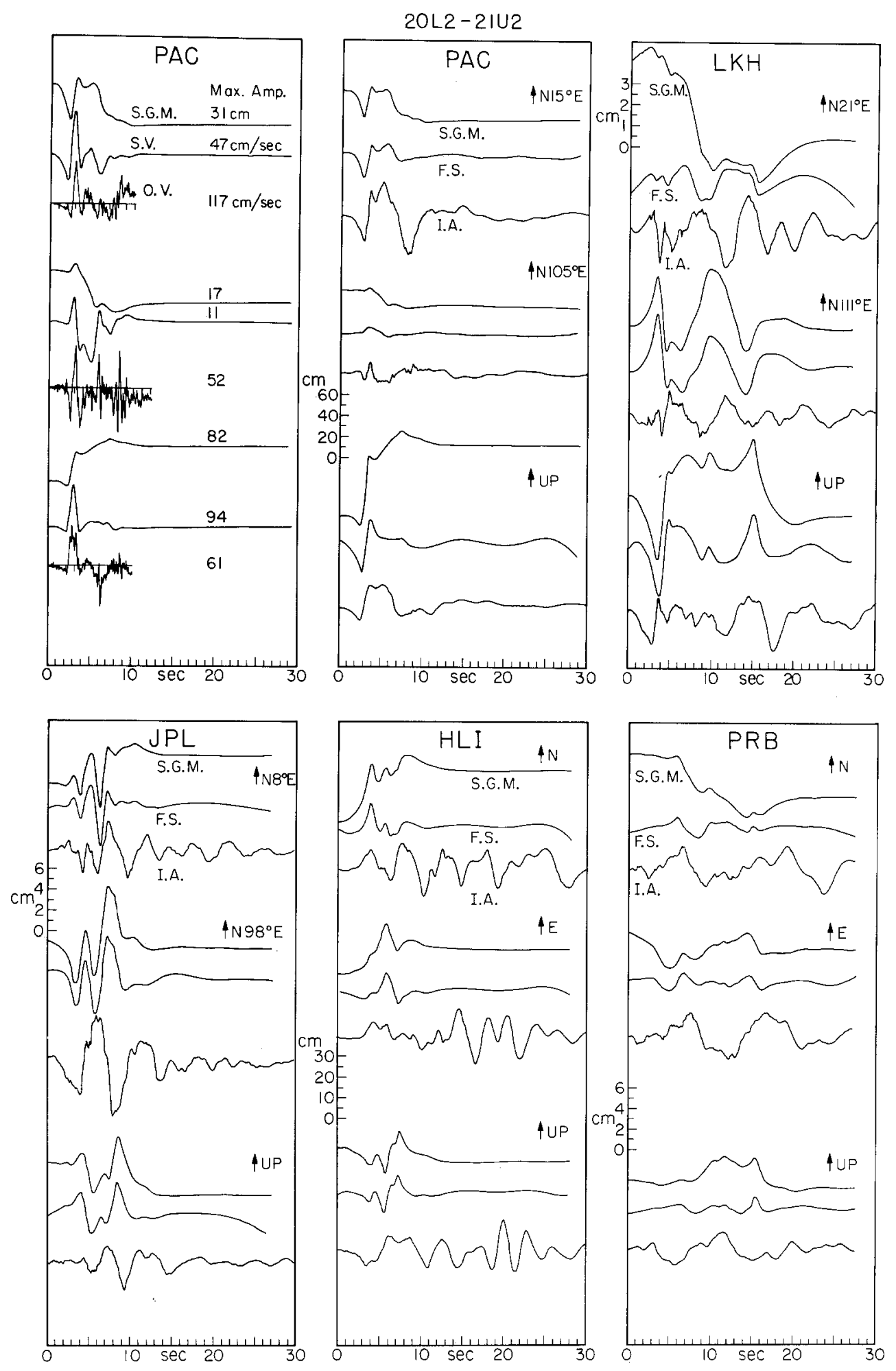

FIG. 10. Synthetic and observed strong ground motion for 20L2-21U2. Except for top left-hand corner, the same scheme as for Figure 3 is used. In the top left-hand corner, S.G.M. refers to synthetic ground motion, S.V. refers to synthetic ground velocity, and O.V. refers to observed ground velocity. Amplitudes of the ground velocities have been normalized, and the peak amplitudes are given for each trace. Amplitudes of ground displacements are absolute and are plotted relative to the scale given for each station. 
produced by an $S V$ wave which is generated by rupture traveling up the Sierra Madre fault zone. Because I have assumed a homogeneous half-space in my model, this ray travels a straight path between the source and receiver. However, if I were to include a velocity gradient near the earth's surface, then rays would steepen their incidence angle as they approached the free surface, thereby increasing the horizontal-to-vertical amplitude ratios for $S V$ waves.

More serious problems arise when trying to explain later parts of the PAC records. There is a distinct negative pulse seen on both the $\mathrm{N} 15^{\circ} \mathrm{E}$ and vertical components about $7 \mathrm{sec}$ into the observed record. In my synthetic records, this pulse is too small on the $\mathrm{N} 15^{\circ} \mathrm{E}$ component and entirely absent on the vertical component. This is a serious shortcoming of the model. Furthermore, it is very difficult to produce the negative pulse seen on the vertical component within the framework of a steeply dipping fault located within a homogeneous half-space. Our previous model, Norma 163 , which included massive faulting at a very shallow depth on a shallow-dipping fault plane, seemed better suited to explain this later part of the record. Remember though, Norma 163 does a miserable job of explaining long-period teleseismic body waves.

Although 20L2-21U2 explains the peak amplitudes at other stations fairly well, it does not match waveforms. Part of the problem is undoubtedly due to complications which are introduced by complex velocity structures. In particular, the station HLI is located within the sediment-filled San Fernando Valley. Although this station is close to the surface rupture, large arrivals are present over $10 \mathrm{sec}$ after motion has ceased on the synthetic records. It seems likely that these are surface waves which have been trapped within the San Fernando Valley. Except for the station HLI, the durations of synthetic records are comparable to the observed durations. In general, though, it is clear that many of the features of 20L2-21U2 cannot be defended on the basis of my ability to match synthetic and observed waveforms.

Static deformations. In Figure 11, I show the static vertical uplift data compiled by Alewine (1974). I also show the calculated uplifts which are produced by $20 \mathrm{~L} 2$ 21U2. For comparison, it may be useful for the reader to make a transparency of this figure so that one contour map can be laid over the other. Although there are differences in detail between synthetic and observed offsets, 20L2-21U2 does a respectable job of explaining these displacements. It does appear that the synthetic displacements do not decay with distance from the fault trace quite as quickly as the observed. The peak offset is also somewhat smaller than observed. Both of these problems could be solved by concentrating more of the moment at shallow depth on the San Fernando fault zone. It can be shown that most of the surface offset is due to rupture on the San Fernando fault zone. The maximum surface offset from the rupture on the Sierra Madre fault zone is a $40-\mathrm{cm}$ uplift which occurs near the north side of the $50-\mathrm{cm}$ contour. Thus, although the effect of the rupture on the Sierra Madre fault zone is small, it does serve to lessen the decay of uplift with distance northward from the surface rupture.

In Figure 12, I show the static vertical displacements which would be produced by our earlier model, Norma 163, and by Langston's model. Notice that the contour interval for Langston's model is $20 \mathrm{~cm}$ compared to the $50 \mathrm{~cm}$ used in the other maps. It is clear that the displacements produced by Langston's model are too small. Since the moment Langston derived from teleseismic body waves was one-half the moment of $20 \mathrm{~L} 2-21 \mathrm{U} 2$, this is not surprising. It should be pointed out, however, that although I am assuming a moment of $1.7 \times 10^{26} \mathrm{dyne}-\mathrm{cm}$ for $20 \mathrm{~L} 2-21 \mathrm{U} 2$, the moment that $I$ would have derived from long-period $P$ waves is $1.0 \times 10^{26}$ dyne-cm. Thus, 
each of the models I have presented indicates significantly smaller moments from teleseismic body wave modeling than from strong motions and static offsets.

Our earlier model, Norma 163, also does a respectable job of matching the observations, although it does appear that the synthetic uplifts decay too rapidly northward from the fault trace. Thus, both Norma 163 and 20L2-21U2 are generally compatible with the uplift data. The major difference is that one model predicts an uplift that decays too rapidly with distance northward, whereas the other predicts
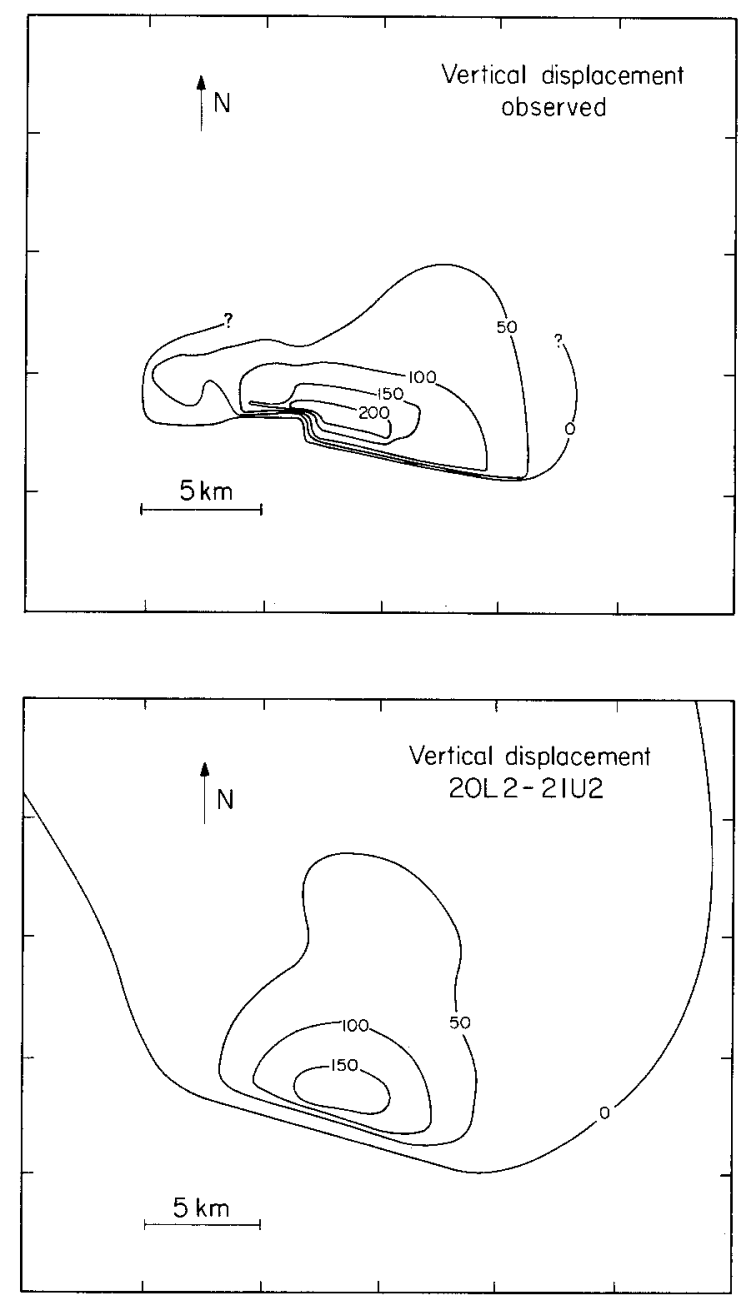

FIG. 11. Contour maps of observed (top) and synthetic (bottom) static vertical displacements assuming model 20L2-21U2. Fifty-centimeter contours are used. The observed data is copied from Alewine (1974).

an uplift which decays too slowly. One can see, though, that the vertical uplift observations alone will not allow differentiation between shallow and steeply dipping fault models.

In Figure 13, I show the north components of the synthetic static displacements for Norma 163 and 20L2-21U2. It is unfortunate that better horizontal offset data are not available because these two models predict significantly different horizontal displacements. In the case of the shallow-dipping fault, Norma 163, the largest offsets occur on the upthrown block. The opposite situation occurs when the fault 

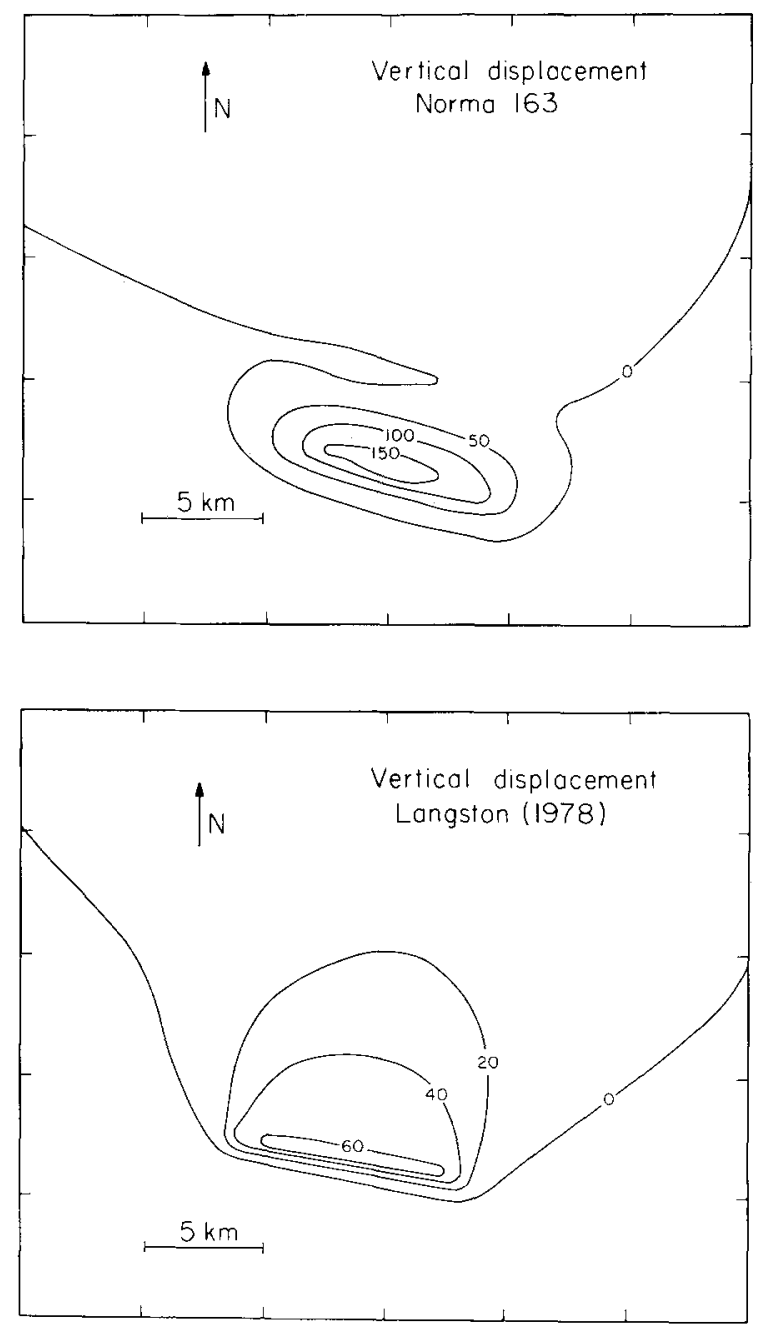

FIG. 12. Contour maps of synthetic static vertical displacements assuming the models Norma 163 (Heaton and Helmberger, 1979) and Langston's (1978) model. Contour intervals are 50 and $20 \mathrm{~cm}$, respectively.

dip is increased (20L2-21U2); then the largest offsets occur south of the surface faulting.

\section{Discussion}

I have presented several models of the San Fernando earthquake which consist of fairly complex three-dimensional sources located in a homogeneous half-space. Using these models, I have produced synthetic records of long-period teleseismic body waves, strong ground motions, and static free-surface deformations. None of the models presented here adequately explain all of the data used in this study. This is somewhat disappointing, but not too surprising. Our trial-and-error method of discovering models is cumbersome and inadequate, considering the large data set we are attempting to understand. Furthermore, our simplistic assumption that the earth can be approximated as a homogeneous half-space is for some, if not most, 
observations difficult to justify. If we are to have any hope of deducing the detailed history of faulting, then we must first evaluate the effects of complex and laterally varying seismic velocities, irregular free-surface topography, and anelastic wave attenuation. Even if these effects were accurately included in our models, we would still need to solve an intricate and perhaps unstable inverse problem in order to discover which source models are consistent with the data. Obviously, the present study is far too simplistic to allow me to state definitively the nature of the faulting history of the San Fernando earthquake.
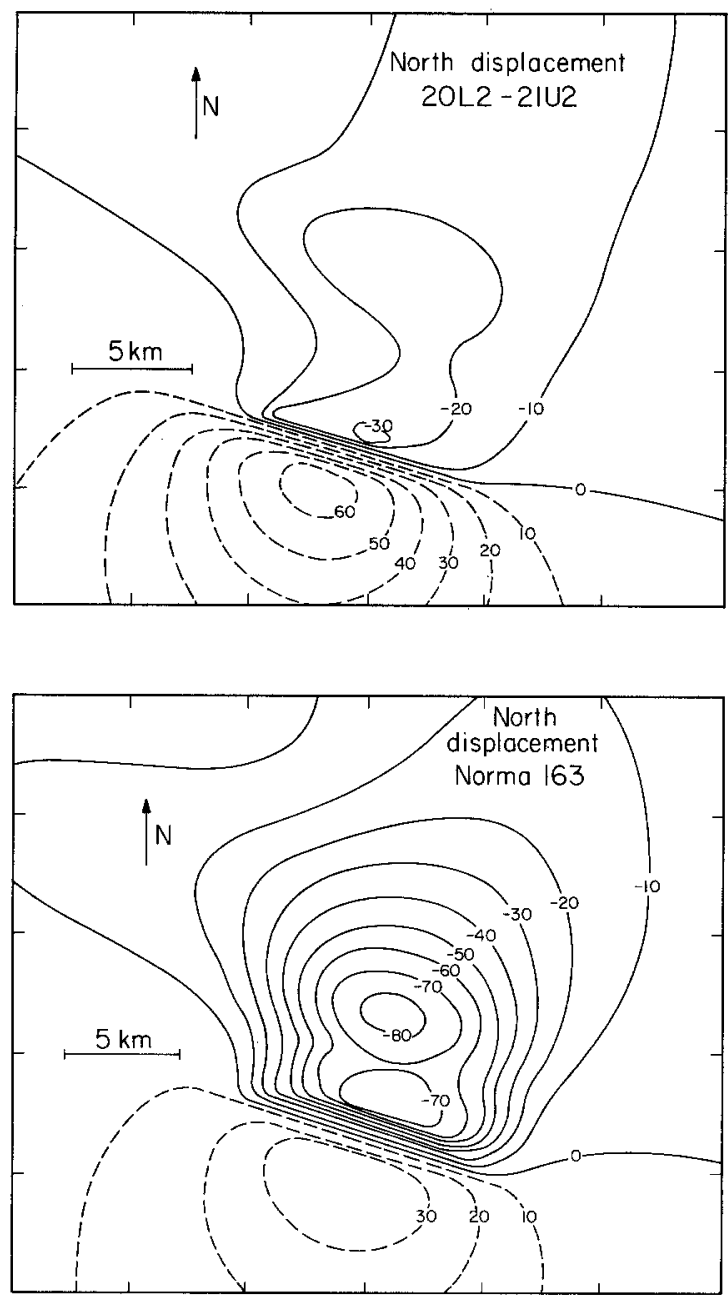

Fig. 13. Contour maps of north components of synthetic static displacements assuming the models Norma 163 and 20L2-21U2. The contour interval is $10 \mathrm{~cm}$, and positive values signify northward motion.

Now that I have disclaimed my ability to derive a complete picture of the faulting, I will attempt to assess lessons which can be learned from this study. Perhaps the most obvious conclusion is that modeling long-period teleseismic body waves does not necessarily provide unique solutions. Despite significant differences between Langston's (1978) model and 20L2-21U2, there is little overall difference in the degree to which they fit long-period teleseismic body-wave data. Although there is little doubt that much can be learned from constructing a model which explains 
teleseismic body waves, it is important to recognize that it can be very difficult to determine a unique faulting history from these models. The same conclusion also applies to the modeling of strong ground motions. The fact that the model proposed in our earlier study of strong ground motion could not explain teleseismic body waves demonstrates the importance of employing different types of data in concert when trying to deduce the seismic source. Since none of the models proposed to date adequately explain most of the observed strong ground motions (in the sense of fitting waveforms), I can hardly claim that a unique solution cannot be obtained from this data set. Certainly there is a tremendous amount of information contained in this data set. Seismic energy which has left the source region over a wide range of azimuths, take-off angles, and frequencies are represented in this data set. Unfortunately, our poor understanding of the effects of wave propagation through the real earth limits our ability to interpret the meaning of these records. Through the course of a long study in which trial and error are used, we have managed to fit nearly all of the records very well. Unfortunately, in the course of fitting one record, we also unfit others. This process tends to make one very suspicious of studies in which source models are derived on the basis of one or even two stations.

What about the San Fernando earthquake? What can I say about the faulting history? On the basis of the teleseismic long-period body waves, it appears that the earthquake can be thought of as basically a double event. This is compatible with the fact that the up-dip projection of the focal mechanism does not coincide with the observed surface rupture. Since the up-dip projection of the focal mechanism coincides with the Sierra Madre fault zone, it seems likely that rupture initiated on this fault. A fairly high rupture velocity (greater than $2.5 \mathrm{~km} / \mathrm{sec}$ ) seems necessary to provide sufficient directivity to explain the large velocity pulses observed at Pacoima Dam. Vertical uplift data, in conjunction with strong-motion data, suggest that the majority of faulting on the Sierra Madre fault zone occurred between depths of 3 and $16 \mathrm{~km}$. The moment is probably between 0.5 and $1.0 \times 10^{26}$ dyne-cm and is constrained primarily by the strong-motion data. Because of the large disparity in peak velocities recorded at PAC and LKH, it is necessary to model the faulting width as less than $10 \mathrm{~km}$ in order to enhance directivity effects. Although this model for the first event seems compatible with most of the data used in this study, my modeling study is certainly not complete enough to allow me to claim that I have uniquely determined the characteristics of this first event.

This model also contains a second and larger event which initiates about $4 \mathrm{sec}$ after the first. There is considerable circumstantial evidence that rupture on the San Fernando fault zone is associated with this second event. Vertical uplifts of more than $2 \mathrm{~m}$ occurred on the upthrown block, indicating substantial faulting at shallow depths. Evidence for this later shallow faulting can also be found in both the teleseismic body-wave modeling and the strong-motion modeling. Modeling of teleseismic body waves further indicates that a significant portion of this faulting occurred at depths greater than $3 \mathrm{~km}$.

The dip of the San Fernando fault is of considerable interest and is also poorly known. Although it is possible to construct models with shallow dip angles (less than $30^{\circ}$ ) which explain teleseismic body-wave data, strong-motion data, and staticoffset data, it is difficult to satisfy all of these data with a single model which assumes a shallow dip on the fault plane. If a shallow dip is assumed, then modeling of strong-motion data and static-uplift data indicates that most of the faulting occurred at depths of less than $3 \mathrm{~km}$. This conclusion is incompatible with the modeling of teleseismic body waves. 
If the dip of the San Fernando fault zone is assumed to be between $40^{\circ}$ and $50^{\circ}$, then the depth constraint imposed by the strong-motion and static-uplift data is relaxed, and it is possible to construct models which are consistent with a broader range of data. Although surface faulting along the San Fernando fault zone was observed to be highly variable (ranging from $15^{\circ}$ to $60^{\circ}$ according to Bonilla et al. (1971); Kamb et al. (1971), Bonilla et al. (1971) conclude that the surface faulting was characterized by left-reverse oblique slip along a plane dipping approximately $55^{\circ} \mathrm{N}$. Thus, the observed surface faulting is compatible with the notion that the San Fernando earthquake consisted of two events on subparallel steeply dipping fault planes.

\section{ConCLUSIONS}

Despite $10 \mathrm{yr}$ of study centered on the San Fernando earthquake, there is still considerable uncertainty concerning the faulting history of this earthquake. I have shown that our previous model (Heaton and Helmberger, 1979) is not compatible with long-period teleseismic body-wave observations. Furthermore, I have demonstrated that modeling teleseismic and near-field data with a fault model which incorporates a shallow dip (less than $30^{\circ}$ ) on the San Fernando fault results in mutually incompatible results concerning the depth distribution of faulting. In order to alleviate this problem, I propose a model in which I assume that the San Fernando earthquake occurred on two subparallel steeply dipping thrust faults. I hypothesize that rupture initiated on the Sierra Madre fault zone, propagated to within $3 \mathrm{~km}$ of the surface, and had a rupture velocity of approximately $2.8 \mathrm{~km} / \mathrm{sec}$ and a moment of $0.7 \times 10^{26}$ dyne-cm. I believe that the strong velocity pulse at Pacoima Dam is due to an $S V$ wave caused by rupture on the Sierra Madre fault zone and enhanced by directivity. This part of the model is essentially unchanged from our previous model (Heaton and Helmberger, 1979). I propose that rupture on the San Fernando fault initiated about $4 \mathrm{sec}$ after the initiation of rupture on the Sierrra Madre fault zone and that rupture then propagated from a depth of about $8 \mathrm{~km}$ to the earth's surface at a rupture velocity of $2.8 \mathrm{~km} / \mathrm{sec}$. The moment of this second event appears to be about $1.0 \times 10^{26}$ dyne-cm. In my model, the dip angle of the San Fernando fault is $45^{\circ}$, which is significantly steeper than that assumed in our earlier study. Although there are many features of the observed data which are not predicted by this model, I believe that, in an overall sense, it is compatible with more data than previous models. Therefore, I feel that future studies of this data set should consider the possibility that the San Fernando earthquake occurred as a double event: an initial event on the Sierra Madre fault zone followed shortly thereafter by a slightly larger event on the San Fernando fault zone.

\section{ACKNOWLEDGMENTS}

I wish to thank Paul Spudich and William Bakun for critically reviewing the manuscript. I also wish to thank Donald Helmberger, Charles Langston, Steve Hartzell, and Thomas Hanks for useful discussions. Although this study was completed while I was an employee of the U.S. Geological Survey, major portions of the work were completed when I was employed by Dames and Moore and also by the California Institute of Technology. Thus, I give special thanks to Arthur Darrow and Donald Helmberger for their support of this research. This research was partially supported by the National Science Foundation Contract PFR-7808813.

\section{REFERENCES}

Alewine, R. W., III (1974). Application of linear inversion theory toward the estimation of seismic source parameters, Ph.D. Thesis, California Institute of Technology, Pasadena, 303 pp.

Allen, C. R., T. C. Hanks, and J. C. Whitcomb (1973). San Fernando earthquake: seismological studies 
and their implications, in San Fernando California, Earthquake of February 9, 1971, vol. 1, Geological and Geophysical Studies, U.S. Government Printing Office, Washington, D.C.

Bache, T. C. and T. G. Barker (1978). The San Fernando earthquake-A model consistent with nearfield and far-field observations at long and short periods, Systems, Science and Software, Final Technical Report to the U.S. Geological Survey, Contract No. 14-08-0001-15887, 132 pp.

Bonilla, M. G., J. M. Buchanan, R. O. Castle, M. M. Clark, V. A. Frizell, R. M. Gulliver, F. K. Miller, J. P. Pinkerton, D. C. Ross, R. V. Sharp, R. F. Yerkes, and J. I. Ziony (1971). Surface faulting, U.S. Geol. Surv. Profess. Paper 733, 55-76.

Boore, D. M. and M. D. Zoback (1974). Near-field motions from kinematic models of propagating faults, Bull. Seism. Soc. Am. 64, 321-342.

Bouchon, M. and K. Aki (1977). Discrete wave number representation of seismic source wavefields, Bull. Seism. Soc. Am. 67, 259-277.

Burdick, L. J. and C. A. Langston (1977). Modeling crustal structure through the use of converted phases in teleseismic body-wave forms, Bull. Seism. Soc. Am. 67, 677-691.

Carpenter, E. W. (1966). Absorption of elastic waves-An operator for a constant Q mechanism, Atomic Weapons Research Establishment, Report 0-4366, Her Majesty's Station Office, London, England.

Futterman, W. I. (1962). Dispersive body waves, J. Geophys. Res. 67, 5279-5291.

Hanks, T. C. (1975). Strong ground motion of the San Fernando California earthquake: ground displacements, Bull. Seism. Soc. Am. 65, 193-225.

Heaton, T. H. (1978). Generalized ray models of strong ground motion, Ph.D. Thesis, California Institute of Technology, Pasadena, 292 pp.

Heaton, T. H. and D. V. Helmberger (1979). Generalized ray models of the San Fernando earthquake, Bull. Seism. Soc. Am. 69, 1311-1341.

Helmberger, D. V. (1968). The crust-mantle transition in the Bering Sea, Bull. Seism. Soc. Am. 58, 179-214.

Kamb, B., L. T. Silver, M. J. Abrams, B. A. Carter, T. H. Jordan, and J. B. Minster (1971). Pattern of faulting and nature of fault movement in the San Fernando earthquake, U.S. Geol. Surv. Profess. Paper 733, 41-54.

Langston, C. A. (1976). Body wave synthesis for shallow earthquake sources: inversion of source and earth structure parameters, Ph.D. Thesis, California Institute of Technology, Pasadena, $214 \mathrm{pp}$.

Langston, C. A. (1978). The February 9, 1971, San Fernando earthquake: a study of source finiteness in teleseismic body waves, Bull. Seism. Soc. Am. 68, 1-29.

Langston, C. A. and D. V. Helmberger (1975). A procedure for modeling shallow dislocation sources, Geophys. J. 42, 117-130.

Mansinha, L. and D. E. Smylie (1971). The displacement fields of inclined faults, Bull. Seism. Soc. Am. 61, 1433-1440.

Nigam, N. C. and P. C. Jennings (1968). Digital calculation of response spectra from strong-motion earthquake records, Report from the Earthquake Engineering Research Laboratory, California Institute of Technology, Pasadena, $65 \mathrm{pp}$.

Trifunac, M. D. (1971). Zero base-line correction of strong motion accelerograms, Bull. Seism. Soc. Am. 61, 1201-1211.

Trifunac, M. D., F. E. Udwandia, and A. G. Brady (1973a). Analysis of errors in digitized strong-motion accelerograms, Bull. Seism. Soc. Am. 63, 157-187.

Trifunac, M. D., A. G. Brady, and D. E. Huydson (1973b). Strong-motion earthquake accelerograms, corrected accelerograms and integrated ground velocity and displacement curves, vol. II, parts C, G, J, Earthquake Engineering Research Laboratory, EERL 73-75, California Institute of Technology, Pasadena.

Whitcomb, J. H. (1971). Fault-plane solutions of the February 9, 1971, San Fernando earthquake and some aftershocks, U.S. Geol. Surv. Profess. Paper 733, 30-32.

Office of Earthquake Studies

U.S. GEOLOGICAL SURVEY

SEISMOLOGICAL LabORATORY

California Institute of Technology

Pasadena, California 91125

Manuscript received 22 December 1981

\section{APPENDIX}

In this Appendix, I describe the nature of teleseismic body waves which are produced by a three-dimensional finite fault having an arbitrary history of disloca- 
tions. Consider the fault geometry shown in Figure A1. If we merely assume a linear system, then the observed displacement history, $U(t)$, at some receiver can be written,

$$
\boldsymbol{U}(t)=\int_{0}^{l} \int_{0}^{w} \boldsymbol{u}(x, y, t) d y d x
$$

where $x$ and $y$ run along the fault strike and plunge, respectively, where $l$ and $w$ are the fault length and width, respectively; and where $u(x, y, t)$ is the receiver displacement history due to the dislocation at the point $(x, y)$ on the fault. If, for simplicity, we assume that the dislocation vectors are everywhere parallel, then equation (1) can be rewritten

$$
\boldsymbol{U}(t)=\int_{0}^{l} \int_{0}^{w} \dot{D}(x, y, t) * \boldsymbol{G}(x, y, t) d y d x
$$

where $D(x, y, t)$ is the location time history for each point on the fault, $G(x, y, t)$ is

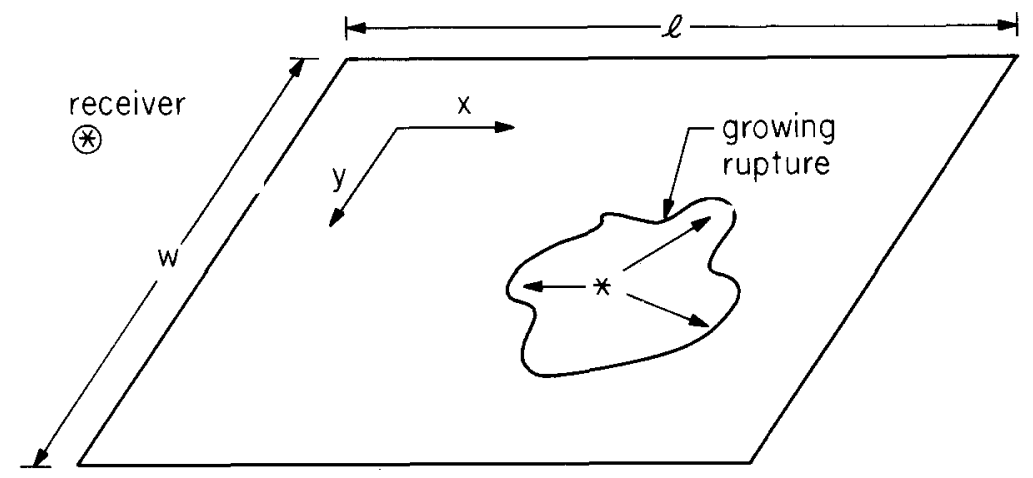

FIG. A1. Simplified finite fault geometry. See text for explanation of symbols.

the displacement at the receiver due to a point dislocation at $(x, y)$ that has a unit step function time history, and $\cdot$ and $*$ signify time differentiation and convolution operators, respectively.

Equation (A2) is quite general and applies to both near and distant observations. In the case of strong motions, very few approximations can be made and this integral must be calculated numerically (see Bouchon and Aki, 1977 for some exceptions to this generality). Let us assume that we are dealing with a vertically layered space, and, for simplicity, let us also assume that the fault is confined to lie within a single layer. We can decompose the point response $G(x, y, t)$ into an infinite sum over generalized rays (Helmberger, 1968) as follows,

$$
\boldsymbol{G}(x, y, t)=\sum_{i=1}^{\infty} \boldsymbol{G}_{i}(x, y, t)
$$

where $i$ indexes all possible generalized rays.

If we are viewing only body waves at great distance, then we can make the following approximation,

$$
\boldsymbol{G}_{i}(x, y, t) \simeq \boldsymbol{G}_{i}\left[x_{0}, y_{0}, t-T_{i}(x, y)\right]
$$


where $\left(x_{0}, y_{0}\right)$ is some point on the fault plane, and $T_{i}(x, y)$ is the arrival time difference for two identical rays arriving from the points $(x, y)$ and $\left(x_{0}, y_{0}\right)$. We can immediately rewrite this approximation as

$$
\boldsymbol{G}_{i}(x, y, t) \simeq \mathbf{G}_{i}\left(x_{0}, y_{0}, t\right) * \delta\left[t-T_{i}(x, y)\right],
$$

where $\delta$ is a Dirac delta function. Substituting equation (A5) into (A3) into (A2), we obtain,

$$
\begin{aligned}
U(t) & \simeq \int_{0}^{l} \int_{0}^{w} \sum_{i=1}^{\infty} G_{i}\left(x_{0}, y_{0}, t\right) * \delta\left[t-T_{i}(x, y)\right] * \dot{D}(y, y, t) d y d x \\
& =\sum_{i=1}^{\infty}\left\{G_{i}\left(x_{0}, y_{0}, t\right) * \int_{0}^{l} \int_{0}^{w} \dot{D}\left[x, y, t-T_{i}(x, y)\right] d y d x\right\} \\
& =\sum_{i=1}^{\infty} G_{i}\left(x_{0}, y_{0}, t\right) * F_{i}(t),
\end{aligned}
$$

where

$$
F_{i}(t) \equiv \int_{0}^{l} \int_{0}^{w} \dot{D}\left[x, y, t-T_{i}(x, y)\right] d y d x
$$

$F_{i}(t)$ is called the far-field time function for the $i$ th ray. If we use the first-motion approximation appropriate for teleseismic body waves (Langston and Helmberger, 1975), then the solution becomes particularly simple.

$$
\boldsymbol{G}_{i}\left(x_{0}, y_{0}, t\right) \simeq \boldsymbol{A}_{i} \delta\left(t-\tau_{i}\right) * Q_{i}(t),
$$

and, thus,

$$
\boldsymbol{U}(t) \simeq \sum_{i=1}^{\infty} \boldsymbol{A}_{i} F_{i}\left(t-\tau_{i}\right) * Q_{i}(t)
$$

where $\boldsymbol{A}_{i}$ is a vector pointed along the $\boldsymbol{P}$-wave particle motion having an amplitude which includes the effects of radiation pattern, reflection and transmission coefficients, and geometric spreading. $\tau_{i}$ is the hypocentral travel time of the $i$ th ray and $Q_{i}(t)$ is an attenuation operator, which in this study I assume to be the Futterman $Q$ operator (Futterman, 1962) with constant $t^{*}=T / Q$ (Carpenter, 1966), where $T$ is the ray travel time, and $Q$ is the average seismic quality factor along the ray. In this study, values of $t^{*}$ of 1.2 and 4.8 are assumed for the $P$ and $S$ waves, respectively.

In the teleseismic body-wave problem, there are no critical angle reflections. Thus, the amplitude of rays with multiple reflections becomes very small, and the condition that we sum over an infinite number of rays can be easily relaxed to a summation over a finite number of rays. Furthermore, we need not compute a new far-field time function for each additional ray since rays having similar ray parameters have similar time functions. For instance, the far-field time functions will be nearly identical for all rays which begin as upgoing $P$ waves and which also leave the source region as $P$ waves. Other wave types can also be grouped according to ray parameter, and a single-time function can be found which is appropriate for each group. If the source involves faulting in more than one layer, then the solution 
can be constructed by simply summing the contributions of individual finite faults, each of which represents faulting in an individual layer.

In this study, I consider the near-source structure to be a simple half-space and, thus, only six rays are required to represent the solution completely. For instance, I can write the teleseismic $P$-wave solution as

$$
\boldsymbol{U}_{p} \simeq\left[\boldsymbol{A}_{p} F_{p}\left(t-T_{p}\right)+\boldsymbol{A}_{p P} \boldsymbol{F}_{p P}\left(t-T_{p P}\right)+\boldsymbol{A}_{s P} F_{s P}\left(t-\boldsymbol{T}_{S P}\right)\right] * Q_{P}(t),
$$

where the subscripts, $P, p P$, and $s P$ denote the phases which contribute to the $P$ wave train for shallow seismic sources in a half-space. These phases are illustrated in Figure A2.

I show some examples in Figure A3 of how teleseismic long-period $P$ waves are generated using this technique. I assume a vertical strike-slip fault with a circular rupture whose diameter is $12 \mathrm{~km}$ and whose center is located at a depth of $7 \mathrm{~km}$. The observer is located at a distance of $58^{\circ}$ directly along the fault strike. The rupture velocity is assumed to be $2.5 \mathrm{~kg} / \mathrm{sec}$, and the fault slip is assumed to be uniform everywhere with a time history whose time derivative is an isosceles triangle of 1-sec duration. In Figure A3, I show the far-field time functions and the final

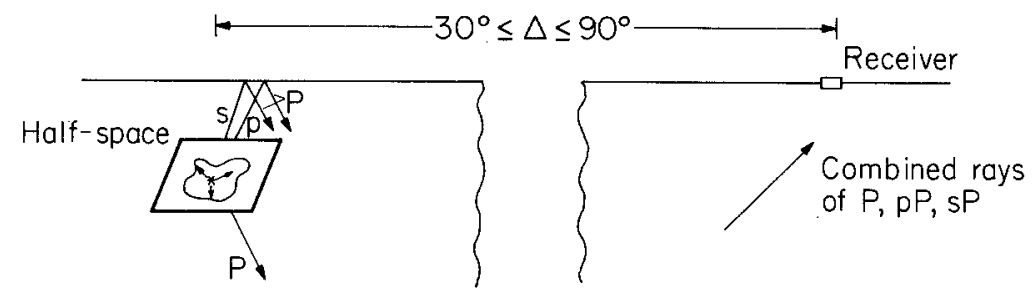

FIG. A2. Phases which contribute to teleseismic $P$ wave train when the source is located in a halfspace (modified from Langston, 1976). See text for explanation of symbols.

responses of individual rays as well as the total final vertical long-period $P$ waveforms for models which differ only in the location of their hypocenters.

An inspection of the synthetics in Figure A3 yields insight into the role of directivity in long-period teleseismic waveforms. The difference in the durations of the far-field time functions for individual rays can be attributed to directivity. It is easy to see that directivity is far more important in cases where rupture proceeds unilaterally up- or down-dip, than in cases where rupture proceeds along the strike. This can be attributed to the fact that, for waves viewed teleseismically, the horizontal phase velocity of wave fronts is much higher than the vertical phase velocity. Directivity only plays an important role when the rupture front progresses at a velocity which is roughly comparable with the seismic phase of interest. If the rupture velocity is very low, then all time function durations are controlled mainly by the total rupture time of the earthquake.

Although directivity plays an important role in cases where rupture proceeds upor down-dip, the relative timing of the major phases also has an important effect. This timing is mainly controlled by hypocentral depth. The important effect of hypocentral depth has been included in studies where earthquakes are modeled as infinitesimal point sources. The effects of directivity can only be seen in those cases 

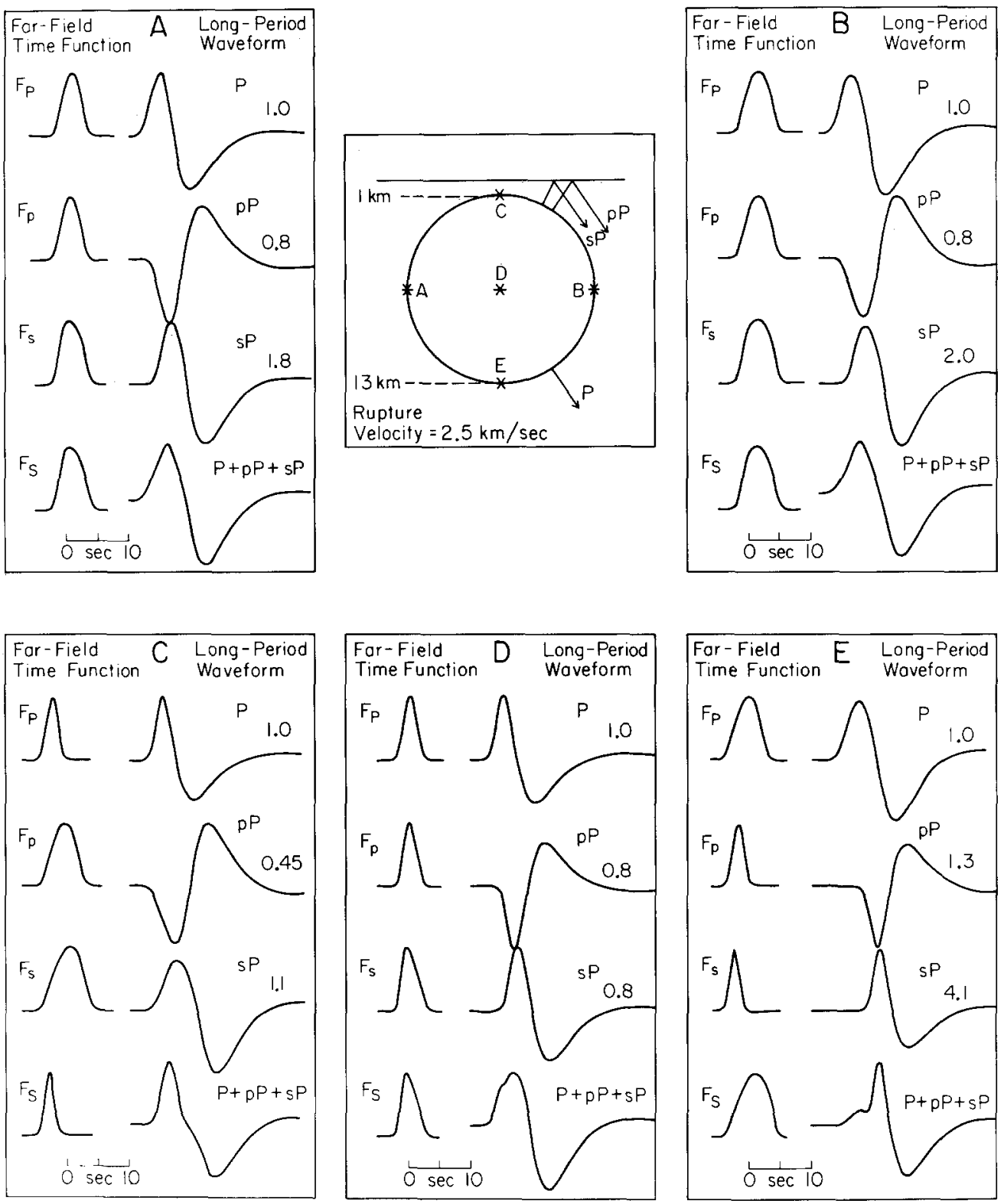

FIG. A3. Illustration showing the effects of directivity and hypocentral depth on teleseismic longperiod waveforms. Teleseismic vertical $P$ waveforms are shown for four identical circular vertical strikeslip faults of diameter $10 \mathrm{~km}$. The only difference from one model to the next is the location of the hypocenter. Theoretical far-field time functions for individual phases are shown on the left. Synthetic seismograms (including $Q$ and instrument) for individual phases are shown on the right. Final synthetic $P$ waveforms are shown at the bottom. See text for explanation of symbols.

where there is a significant variation in the far-field time function from phase to phase or station to station. For instance, when the hypocenter is located at the center of the fault, then there is very little variation in the far-field time function. In such a case, the finite source could be easily approximated by a single-point source, located at a depth of $7 \mathrm{~km}$ and having a far-field time function which is an average 
of the time functions appropriate for each of the phases. It is also worth noting that, for the case of a vertical strike-slip fault, the phase $s P$ is the largest phase seen in the $P$ waveform. This means that much of the $P$ wave train is due to a wave which leaves the source as an $S$ wave. Conversely, teleseismic $S V$ waveforms contain the phase $p S$. Thus, it is not correct to view differences in the frequency content of teleseismic $P$ - and $S$-wave trains as being simply due to differences in the direct $P$ and $S$ waves which are caused by source directivity. Although it is clear that directivity can be important in these models, its effect is complex and depends upon the particular geometry chosen. 